\title{
Predictors of quality of life in patients with diabetic foot ulcer: The role of anxiety, depression, and functionality
}

Journal of Health Psychology I-I I

(c) The Author(s) 2016

Reprints and permissions: sagepub.co.uk/journalsPermissions.nav DOI: $10.1177 / 1359105316656769$ hpq.sagepub.com

(S)SAGE

\author{
Susana Pedras', Rui Carvalho \\ and M. Graça Pereira'
}

\begin{abstract}
The goal of this study was to analyze the relationships between anxiety, depression symptoms, and functionality as predictors of quality of life, in patients with diabetic foot ulcer taking in consideration clinical variables. A sample of 202 participants indicated for a lower limb amputation surgery, were assessed before the surgery, on physical and mental quality of life, functionality, a anxiety and depression symptoms. Anxiety and depression symptoms, as well as functionality level were predictors of mental quality of life. Pain, having a first amputation, depression symptoms, and functionality were predictors of physical quality of life. In order to promote quality of life, psychological variables should be targeted, in clinical practice.
\end{abstract}

\section{Keywords}

anxiety, depression, diabetic foot ulcer, functionality, quality of life

\section{Introduction}

In Europe, 8.3 percent of the adult population has diabetes (International Diabetes Federation (IDF), 2013) and in Portugal, about 13 percent of the population (Portuguese Society of Diabetes, 2015). Diabetic foot is a complication of diabetes and diabetic foot ulcer (DFU) is the term used to name the lesions that can occur in a patient's foot. The foot of a patient with diabetes that has the potential risk of pathologic consequences, including infection, ulceration, destruction of deep tissues associated with neurologic abnormalities, several degrees of peripheral arterial disease, and metabolic complications of diabetes, in the lower limb, is called Diabetic Foot. (Frykberg et al., 2000).
The most frequent etiologies of DFU are neuropathy, trauma, deformity, high plantar pressures, and peripheral arterial disease (Frykberg et al., 2000).

DFU is one of the most serious complications of diabetes and affects 15 percent of patients with diabetes representing the major cause of lower limb amputation from a non-traumatic

\footnotetext{
'University of Minho, School of Psychology, Braga, Portugal

${ }^{2}$ Centro Hospitalar do Porto, Porto, Portugal

Corresponding author:

Susana Pedras, School of Psychology, University of Minho,

Campus de Gualtar, Braga 4710-057, Portugal.

Email: susanapedras@gmail.com
} 
origin (Armstrong et al., 2001). DFU is associated with several comorbidities related with long periods of hospitalization with great impact on the individuals' life, increased economic and social costs (Apelqvist et al., 2008), and a burden for families and the health care system (Margolis et al., 2011). In fact, the negative impact of DFU on patients' health-related quality of life (HRQoL) is a major concern for health professionals.

It is well known that several factors influence the impact of DFU on HRQoL including demographic and clinical characteristics (Ribu et al., 2007), and that DFU patients have an impaired HRQoL when compared with those without DFU (Goodridge et al., 2005, 2006; Ikem et al., 2009; Madanchi et al., 2013; Ribu et al., 2007; Valensi et al., 2005; Yekta et al., 2011). In fact, DFU affects patients' physical HRQoL mainly due to pain and to the reduced level of mobility (Ashford et al., 2000; Ribu and Wahl, 2004; Siersma et al., 2013). The impact of DFU on HRQoL and level of mobility is so strong that amputees who have mobilization capacities have a higher HRQoL than patients with DFU (Carrington et al., 1995, 1996). Pain, which progressively deteriorates the HRQoL of DFU patients, is also a concern for patients and health professionals (Bengtsson et al., 2008; Bradbury and Price, 2011; Siersma et al., 2013; Vileikyte et al., 2005).

Furthermore, DFU negatively affects emotional and psychological functioning (Douglas, 2001; Price, 2004; Ribu et al., 2007; Valensi et al., 2005; Yekta et al., 2011) and the severity of the impact on mental functioning is comparable to other serious medical problems (e.g. cancer) (Armstrong et al., 2007, 2008; NabuursFranssen et al., 2005). Some studies, however, found that patients with DFU showed good mental health (Fejfarová et al., 2014; Meijer et al., 2001; Siersma et al., 2013). Nonetheless, psychological morbidity (anxiety and depression symptoms) is another factor that negatively affects HRQoL in this population, mainly due to reduced mobility (Ikem et al., 2009; Siersma et al., 2013; Vileikyte et al., 2005). Patients with DFU present high levels of anxiety and depression at levels consistent with clinical depression (Chapman et al., 2014; Ismail et al., 2007; Vileikyte et al., 2005). Having a DFU, and the reduced mobility associated with it, is related with depressive symptoms (Williams et al., 2010) which also decrease adherence to foot care behaviors (Iversen et al., 2009; Nam et al., 2011), increasing the risk of poor wound healing and wound recurrence (Monami et al., 2008). In fact, major depression is associated with a twofold higher risk of incidence of DFU (Williams et al., 2010). The literature on anxiety, among patients with diabetes-related foot ulcers, is limited but the few existing studies reveal that anxiety symptoms are more prevalent in patients with unhealed DFU (Ragnarson-Tennvall and Apelqvist, 2000), and no differences have been found in anxiety symptoms between patients with DFU, patients who underwent an amputation or patients with diabetes (Carrington et al., 1996).

A number of publications have addressed the relationship between demographic and clinical factors of HRQoL, in DFU patients (Ikem et al., 2009; Ribu et al., 2007; Valensi et al., 2005; Yekta et al., 2011). However, to our knowledge, no data is currently available regarding the HRQoL of patients with DFU indicated for amputation surgery since they make a specific group. Also, the gap in the literature lies particularly in the absence of studies that explore the impact of psychological factors besides sociodemographic and clinical variables, on HRQoL. It is of great importance to assess the impact of anxiety and depression symptoms with regard to their influence on HRQoL. It is known that the physical quality of life deteriorates more than mental health due to multimorbidity (Fortin et al., 2006). Therefore, this study also took into consideration the role of mobility difficulties as one of the most important determinants of poor HRQoL. According to the biopsychosocial model, the care of individuals with DFU should include not only the management of physical symptoms, but also a focus on the psychological and social factors (Engel, 1977), that may interfere with the effectiveness of treatments, adherence to self-care behaviors, and wound healing 
(Vedhara et al., 2010). Thus, the purpose of this study was to enhance the understanding of the impact of psychological morbidity and functionality on HRQoL, in DFU patients scheduled for amputation. Knowing the predictors of mental and physical HRQoL will allow the identification of targets to promote HRQoL, in this population. It is hypothesized that DFU patients will show an impaired HRQoL and that anxiety and depression symptoms, as well as functionality, will contribute to both physical and mental HRQoL.

\section{Methods}

\section{Procedure}

This study was conducted in six hospitals, in northern Portugal, within Multidisciplinary Diabetic Foot Clinics and/or Vascular Surgery Departments. This was a cross-sectional study although it is part of an ongoing longitudinal design, and was performed between June 2013 and September 2015. Participation was voluntary and involved the signing of a written informed consent and approval by the Hospital Research Ethics Committee. Participants were assessed in the hospital after knowing they needed an amputation. Health professionals identified 277 participants that met the following inclusion criteria: having type 2 diabetes mellitus (T2DM) and DFU, be indicated for an amputation surgery, and be more than 18 years old. Exclusion criteria included a diagnosis of dementia or a psychiatric disorder. Clinical data for each patient was collected from clinical records, as well as information regarding the level of cognitive impairment (e.g. dementia) and the presence of severe psychiatric disorders (e.g. schizophrenia).

\section{Sample}

A consecutive sample, of 202 participants with T2DM and DFU scheduled for a lower limb amputation, was enrolled in the study and assessed on hospital admission. From 277 patients who were identified by health professionals to comprise the study, only 202 participated since 75 (37\%), were not included due to several reasons: 39 participants had cognitive impairment; 7 refused participation, 5 had their surgeries canceled; 2 died prior to surgery; 1 patient was in the intensive care unit; 2 participants were transferred to a different hospital; 2 participants showed hearing loss, and 17 received emergency amputations and were excluded due to procedural reasons.

\section{Instruments}

Socio demographic and clinical questionnaire. This instrument included questions on gender, age, education, marital, and professional status. The clinical section asked questions concerning diabetes and DFU onset, presence of other diabetes complications other than neuropathy and vascular disease (nephropathy and nephrology), and presence of other medical conditions than diabetes and its complications, type of foot, ulcer duration and location, number of hospitalizations in the previous year, duration of the current hospital admission, body mass index (BMI), presence and duration of pain, and number of previous amputations. Pain was assessed through a question with a dichotomous answer $(y / n)$. Type of foot was classified as neuropathic or neuroischemic. The main difference between the two types of diabetic foot lies in the absence or presence of pulses; the neuropathic foot has peripheral pulses and loss of sensation while the neuroischemic foot has no pulses (Edmonds and Foster, 2006).

Hospital Anxiety and Depression Scale. This scale assesses psychological morbidity (depression and anxiety) on a 14-item scale: seven items for anxiety (e.g. "I feel tense or wound up"; "Worrying thoughts go through my mind") and seven items for depression (e.g. "I enjoy the things I used to enjoy"; "I have lost interest in my appearance") (Zigmond and Snaith, 1983; Portuguese adapted Version of PaisRibeiro et al., 2007). The score for each scale ranges from 0 to 21 and each item has a choice of four response statements (scored 0-3). Higher scores indicate higher levels of anxiety 
and depressive symptoms, respectively. The Portuguese validation included an inspection for lexical equivalence and content validity, cognitive debriefing, exploratory and confirmatory factor analysis, as well as sensibility. The Portuguese adaptation showed metric properties similar to those in international studies, suggesting that the constructs are measured the same way as the original HADS. A score above 11 is the cutoff for the presence of clinical depressive and anxiety symptoms or a mood disorder in the Portuguese validation (PaisRibeiro et al., 2007). In this study, Cronbach's alpha for the anxiety scale was .85 and .88 for the depression scale.

Barthel Index. This scale assesses the functionality level for activities of daily living (ADLs), such as the functionality to transfer, mobility, bladder and bowel control, grooming, dressing, feeding, bathing, toilet use, and stair climbing (Mahoney and Barthel, 1965; Portuguese Version of Araújo et al., 2007). The scale comprises 10 items. Typical Barthel Index (BI) items are as follows: feeding, 0: "unable"; 1: "needs help cutting"; 2: "independent." Responses range from: 0 to 3 or 0 to 2 , according to the number of items with the total possible scores ranging from 0 to 20 . Lower scores indicate increased disability and higher scores indicate higher levels of functionality and independence. In this study, Cronbach's alpha for the scale was .87 . According to the adapted Portuguese version, the cutoff scores are as follows: 0-8: "dependency"; 9-12: "severe dependency"; 13-19: "mild dependency"; and 20: "independency" (Araújo et al., 2007).

Short-Form Health Survey 36. This scale assesses quality of life and comprises 11 items, 36 questions, and two summary measures that aggregate eight scales (Ware et al., 1993; Portuguese adapted version of Ferreira et al., 2012). The scale has a self-evaluated health transition item with five response categories ranging from "much better" to "much worse," which is not used in scoring the scales or summary measures. The Physical Component Score (PCS) comprises 21 items and includes four scales: Physical Functioning, Role Physical, General Health, and Bodily Pain scales (e.g. "During the past 4 weeks, how often have you experienced any of the following problems with your work or other regular daily activities as a result of your physical health?"; "During the past 4 weeks, how much has pain interfered with your normal work (including both work outside the home and housework)?" Responses, in the Likert scale ranged from, "all of the time $=1$," "most of the time $=2$," "sometime $=3$," "a little of the time $=4$," and "none of the time $=5$ " and "not at all =1," "a little $b i t=2, "$ "moderately $=3$," "quite a bit $=4$," and "extremely $=5$," respectively. The Mental Component Score (MCS) comprises 14 items ans includes four scales: Vitality, Social Functioning, Emotional Role and Mental Health. Typical MCS items are as follows: "During the past 4 weeks, how long have you had any of the following problems with your work or other regular daily activities as a result of any emotional problems (such as feeling depressed or anxious)?" and "Have you been very nervous?" Responses in the Likert scale, ranged from, "all of the time," "most of the time," "some time," "a little of the time," and "none of the time." In this study, only the two summary components were used. Total possible scores range from 21 to 87 in the PCS and from 14 to 70 in MCS, with a higher score indicating a higher HRQoL. The scores in both summary measures were transformed into a scale of $0-100$ (raw score) following the instrument's guidelines and results were analyzed in terms of being above or below the 50th percentile. The Cronbach's alpha in this study, .89 for both PCS and MCS.

\section{Data analysis}

Analyses were conducted using SPSS version 22 (IBM Corporation, 2013). Descriptive sociodemographic clinical data and psychosocial variables are presented as means and standard deviations (SDs). The cutoff points 
Table I. Sample demographic and clinical characteristics $(N=202)$.

\begin{tabular}{|c|c|c|c|c|}
\hline & Mean (\%) & SD & Min & Max \\
\hline \multicolumn{5}{|c|}{ Demographic characteristics } \\
\hline Gender (male) & $72.3 \%$ & & & \\
\hline \multicolumn{5}{|c|}{$\begin{array}{l}\text { Marital status (living with } 62.90 \% \\
\text { partner) }\end{array}$} \\
\hline $\begin{array}{l}\text { Professional status } \\
\text { (retired) }\end{array}$ & $75.30 \%$ & & & \\
\hline Age (years) & 66.2 & 10.94 & 36 & 90 \\
\hline Educational level (years) & 4.56 & 3.18 & 0 & 17 \\
\hline \multicolumn{5}{|l|}{ Clinical characteristics } \\
\hline $\begin{array}{l}\text { Duration of diabetes } \\
\text { (months) }\end{array}$ & 224.4 & 138.2 & 1 & 636 \\
\hline $\begin{array}{l}\text { Duration of diabetic } \\
\text { foot (months) }\end{array}$ & 43.70 & 56.0 & 1 & 264 \\
\hline $\begin{array}{l}\text { Ulcer duration: median/ } \\
\text { mean (weeks) }\end{array}$ & $11 / 18.26$ & 22.46 & 1 & 192 \\
\hline \multicolumn{5}{|l|}{ Ulcer location } \\
\hline Toes & $62.90 \%$ & & & \\
\hline Foot & $29.20 \%$ & & & \\
\hline Leg/heel & $8 \%$ & & & \\
\hline $\begin{array}{l}\text { Type of foot: } \\
\text { neuroischemic }\end{array}$ & $74.3 \%$ & & & \\
\hline Retinopathy & $63.4 \%$ & & & \\
\hline Nephropathy & $47 \%$ & & & \\
\hline $\begin{array}{l}\text { Other chronic disease: } \\
\text { no }\end{array}$ & $77.7 \%$ & & & \\
\hline Insulin therapy: yes & $68.3 \%$ & & & \\
\hline Pain: yes & $58.90 \%$ & & & \\
\hline Pain duration (weeks) & 23.1 & 22.0 & 1 & 96 \\
\hline BMI $\left(\mathrm{kg} / \mathrm{m}^{2}\right)$ & 26.99 & 4.63 & 17.19 & 46.28 \\
\hline
\end{tabular}

of the instruments were used to characterize HRQoL, clinical symptoms of anxiety and depression, and functionality level. To analyze the relationships among demographic, clinical, and psychological variables, Pearson and Point Bisserial correlations were performed for interval and dichotomous variables, respectively. In order to find the best predictors of MCS and PCS, a hierarchical regression analysis was conducted. The variables correlated with MCS and PCS were included in the model as well as the variable, "having a first amputation" which was not related either with MCS or PCS but due to its relevance in the literature, was added to both models. Therefore, the first step included sociodemographic variables, the second step
Table 2. Descriptive statistics for psychosocial variables.

\begin{tabular}{lrrrr}
\hline Measure & Min & Max & Mean & \multicolumn{1}{c}{ SD } \\
\hline PCS & 21 & 87 & 45.13 & 12.46 \\
MCS & 14 & 70 & 43.05 & 11.64 \\
Anxiety symptoms & 0 & 21 & 11.46 & 5.14 \\
Depressive symptoms & 0 & 21 & 9.34 & 5.90 \\
Functionality & 0 & 20 & 15.52 & 3.73 \\
\hline
\end{tabular}

included clinical variables, and the third step included all psychological variables. To control for multicollinearity, the variance inflation factor (VIF) value was established as being below 2 and the tolerance coefficient was set to be greater than .60 .

\section{Results}

\section{Sample demographic and clinical characteristics}

Of the 202 patients, 57.9 percent had already been amputated, in the past. All the participants were taking oral agents. The duration of current admission was 8.98 days (SD: 9.9). Table 1 shows the sociodemographic and clinical characteristics of the sample.

\section{Descriptive statistics for psychosocial variables}

Descriptive statistics for psychosocial variables are presented in Table 2. Short-Form (SF)-36 summary scores after being transformed into a scale ranging from 0 to 100 , with a mean of 50 and a SD of 10, participants scored below the percentile 50 in the PCS (36.56\%) and slightly above in MCS (51.88\%), that is, on average. Taking into account the cutoff score of 11, for the presence of clinical symptoms of anxiety and depression, the proportion of participants with clinical symptoms of anxiety was 59.9 percent and 37.6 percent for clinical depressive symptoms. Regarding the functionality level, only 18.3 percent showed independency, 62.4 percent reported a mild level of dependency, 
14.9 percent, severe dependency, and 4.5 percent were totally dependent.

\section{Relationships between sociodemographic, clinical, and psychosocial variables}

Positive relationships were found between MCS and type of foot $(r=.168, p=.017)$ and functionality $(r=.498, p<.001)$. Negative relationships were found between MCS and gender $(r=-.294, p<.001)$, age $(r=-.191, p=.006)$, number of hospitalizations in the last year $(r=-.194, p=.006)$, presence of pain $(r=-.224$, $p=.001)$, depression $(r=-.720, p<.001)$, and anxiety symptoms $(r=-.498, p<.001)$.

PCS was positively associated with type of foot $(r=.255, \quad p<.001)$ and functionality $(r=.606, p<.001)$ and was negatively associated with gender $(r=-.254, p<.001)$, age $(r=-.307, p<.001)$, number of hospitalizations in the last year $(r=-.273, p<.001)$, presence of pain $(r=-.469, \quad p<.001)$, ulcer duration $(r=-.151, \quad p=.032)$, depression $(r=-.502$, $p<.001)$, and anxiety symptoms $(r=-.267$, $p<.001)$.

\section{Predictors of MCS}

The regression analysis showed that anxiety and depression were negative predictors and that functionality was a positive predictor of MCS. The final model explained 63 percent of the variance $\quad\left(R_{\mathrm{Adj}}^{2}=61, \quad p<.001\right), \quad F(9,192)=35.70$, $p<.001$, and when psychological variables were added to the model, sociodemographic and clinical variables were no longer significant (Table 3).

\section{Predictors of PCS}

The regression analysis showed that pain and depression symptoms were negative predictors and having a first amputation as well as the level of functionality, were positive predictors of PCS. The final model explained 57 percent of the variance $\left(R_{\mathrm{Adj}}^{2}=.54, p<.001\right), F(10,191)=$ 25.02, $p<.001$ (Table 3).

\section{Discussion}

HRQoL is an important health outcome representing the ultimate goal of health promotion interventions (World Health Organization, 2009). Thus, according to SF-36, DFU patients presented a compromised PCS since they scored below percentile 50, and an average MCS since they scored slightly above the percentile 50. Similar findings have been reported by several other studies which found HRQoL scores to be lower for patients with DFU (Ribu et al., 2007; Valensi et al., 2005; Vileikyte et al., 2003, 2005; Yekta et al., 2011). In this study MCS was higher than PCS. This result is interesting, given that the commitment to PCS is obvious and expected in patients with unhealed DFUs, yet MCS was not as compromised as we had expected it to be. However, Meijer et al. (2001) also did not find psychological complaints in patients with DFU and suggested they had accepted the disability and learned to live with their condition.

The results showed a relationship between anxiety symptoms, depression symptoms, functional level, and MCS and PCS, which are in accordance with the literature (Chapman et al., 2014; Ikem et al., 2009; Siersma et al., 2013; Vileikyte et al., 2005; Williams et al., 2010). In fact, this sample is characterized by high levels of clinical symptoms of anxiety and depression during hospitalization due to DFU although the percentage of patients with clinical symptoms of anxiety was higher than the percentage of patients with clinical symptoms of depression. This result should be read in view of the clinical status of patients since they were indicated for an amputation surgery and therefore, might have felt more anxious about their physical condition, having a pessimistic vision of their future's health and concerned whether they would be able to change their lifestyle. Also, these patients were waiting for a surgery, in the following days and, therefore, might be experiencing high levels of pre-surgery anxiety (Bally et al., 2003). Concerning functionality level, 81.7 percent of patients showed some degree of dependence on ADLs, which confirms the negative impact and 
Table 3. Hierarchical multiple regression with MCS and PCS as dependent variables $(N=202)$.

\begin{tabular}{|c|c|c|c|c|c|c|c|c|c|c|}
\hline Variables & B & SE B & $\beta$ & $R_{\text {Adj }}^{2}$ & $\Delta R^{2}$ & B & SE B & $\beta$ & $R_{\mathrm{Adj}}^{2}$ & $\Delta R^{2}$ \\
\hline MCS & & & & & & PCS & & & & \\
\hline I Step & & & & .11 & $.11 * * *$ & I Step & & & .14 & $.15^{* * * *}$ \\
\hline Gender & -7.262 & 1.735 & $-.280 * * *$ & & & -6.422 & 1.823 & $-.23 \mid * *$ & & \\
\hline Age & -0.179 & $0.07 \mid$ & $-.169 *$ & & & -0.328 & 0.075 & $-.288 * * *$ & & \\
\hline 2 Step & & & & .16 & $.07^{* *}$ & 2 Step & & & .37 & $.24 * * *$ \\
\hline Gender & -6.881 & $\mathrm{I} .705$ & $-.265^{* * * *}$ & & & -5.355 & 1.585 & $-.193 * *$ & & \\
\hline Age & -0.135 & 0.074 & -.127 & & & -0.207 & 0.069 & $-.182 * *$ & & \\
\hline Number hospitalizations & -2.513 & 0.944 & $-.185^{* *}$ & & & -3.037 & 0.877 & $-.208^{* *}$ & & \\
\hline Presence of pain ${ }^{\mathrm{a}}$ & -2.940 & 1.638 & -.125 & & & -9.330 & 1.527 & $-.369 * * *$ & & \\
\hline First amputation ${ }^{b}$ & 0.257 & 1.662 & .011 & & & 3.209 & 1.545 & $.127^{*}$ & & \\
\hline Ulcer duration & - & - & - & & & -0.030 & 0.032 & -.055 & & \\
\hline Type of foot ${ }^{c}$ & 2.500 & 1.785 & .094 & & & 3.390 & 1.662 & $.119 *$ & & \\
\hline 3 Step & & & & .61 & $.44 * * *$ & 3 Step & & & .54 & $.18 * * *$ \\
\hline Gender & -1.573 & 1.219 & -.061 & & & -2.224 & $\mathrm{I} .407$ & -.080 & & \\
\hline Age & 0.042 & 0.053 & .039 & & & -0.027 & 0.062 & -.024 & & \\
\hline Number hospitalizations & -0.691 & 0.661 & -.051 & & & -1.470 & 0.764 & -.101 & & \\
\hline Presence of pain ${ }^{\mathrm{a}}$ & -0.795 & 1.137 & -.034 & & & -7.229 & 1.320 & $-.286 * * *$ & & \\
\hline First amputation ${ }^{\mathrm{b}}$ & -0.300 & 1.136 & -.013 & & & 2.820 & 1.313 & $.112 *$ & & \\
\hline Ulcer duration & - & - & - & & & -0.052 & 0.027 & -094 & & \\
\hline Type of foot ${ }^{c}$ & $0.5 \mathrm{II}$ & 1.224 & .019 & & & 2.088 & 1.418 & .073 & & \\
\hline Anxiety & -0.592 & 0.109 & $-.262^{* * *}$ & & & -0.247 & 0.126 & -.102 & & \\
\hline Depression & -1.003 & 0.106 & $-.509 * * *$ & & & -0.357 & 0.123 & $-.169 * *$ & & \\
\hline Functionality & 0.617 & 0.170 & $.198 * * *$ & & & 1.214 & 0.197 & $.363 * * *$ & & \\
\hline
\end{tabular}

aYes $=\mathrm{I} / \mathrm{No}=0$.

${ }^{\mathrm{b}} \mathrm{Yes}=\mathrm{I} / \mathrm{No}=0$.

cNeuropathic foot $=\mathrm{I} / \mathrm{Neuroischemic} \mathrm{foot}=0$.

$*_{p}<.05 ; * * p<.001 ; * * * p<.000$.

the restrictive features of DFU, as previous studies have reported (Reiber et al., 1998). In fact, only a small part of patients were totally functional for ADLs. Given the well-known association between depressive symptoms and reduced mobility, the results found in this sample come as no surprise (Vileikyte et al., 2005). However, contrary to our expectations, a history of previous amputation was not correlated with PCS or MCS. This result should be pursued in future studies.

Regarding the predictors of PCS, the demographic variables such as male gender and being younger, as well as the clinical variables like fewer hospitalizations in the previous year, not having pain, having a neuropathic foot and a first amputation, were significant predictors of PCS, which is in accordance with previous studies (Akca and Cinar, 2008; Mayfield et al., 2003). However, when the psychological variables were added, the variance explained by the model increased, highlighting the role of psychological variables, such as less depression and higher functionality, on PCS. The reduction in mobility and functionality, as well as the adjustment to a new lifestyle, characterized by limitations, are two major risk factors for an increase in depressive symptoms (Vileikyte et al., 2005) and a decrease in PCS (Ashford et al., 2000; Ribu and Wahl, 2004). However, absence of pain and having a first amputation remained predictors of PCS, as expected.

Regarding MCS, only the psychological variables played an important role for physical and mental well-being. As in the prediction model of PCS, the demographic and clinical variables 
were significant predictors until the psychosocial variables were added to the model. As expected, less psychological morbidity and high functionality were significant predictors of MCS. Moreover, and contrary to PCS, in the MCS's prediction model, none of the demographic and clinical variables were significant predictors. Thus, the contribution of psychological variables to MCS was higher than to PCS. Future studies should analyze whether clinical variables play a role as mediators in the relationship between psychological variables and HRQoL.

The results reveal the simultaneous influence of sociodemographic, clinical, and psychological variables on MCS and PCS as the biopsychosocial model advocates. This study has several implications for clinical practice. In patients with DFU, it is important to address patients' clinical and psychological state as well as the level of functionality. In fact, DFU should be considered a lifelong condition since patients with previous ulcers are at a higher risk of developing a new ulcer (Apelqvist et al., 1993), and undergo a contralateral amputation or a reamputation (Johannesson et al., 2009).

HRQoL should be assessed in routine medical care in order to early identify patients at risk of a reduced HRQoL. The assessment of both mental and physical quality of life should also be included in interventions designed to promote HRQoL. Since functionality level and mobility have a great impact on physical and mental health, rehabilitation programs (e.g. physiotherapy, vocational therapy) should be offered in order to enhance independence and decrease the negative impact of disability on HRQoL, in DFU patients. Finally, a multidisciplinary intervention should be mandatory especially for those patients with DFU indicated for lower limb amputation.

\section{Limitations}

The sample was collected only in hospitals in the North of the country. The nature of the study design does not allow causal relationships. Thus, in future studies, it is important to follow patients from pre-surgery to post-surgery during the rehabilitation process in order to explore the contributions of anxiety and depression symptoms as well as functionality on HRQoL, using a longitudinal design. Future studies should also focus on which specific areas of HRQoL are most affected, in this population.

\section{Conclusion}

The results highlight the contribution of psychosocial variables for HRQoL and the need for psychological intervention, in order to decrease anxiety and depression symptoms, in patients with DFU. Results also suggest that rehabilitation programs should begin as early as possible in order to increase functionality for ADLs and promote HRQoL. According to results, the factors that determine HRQoL, in DFU patients, are not only disease specific. Treatment, therefore, should not only be focused on ulcer healing, but also based in a multidisciplinary approach that includes psychological factors.

\section{Acknowledgements}

The authors gratefully acknowledge the contributions of the Multidisciplinary Diabetic Foot Clinics of five hospitals: CHP, CHSJ, CHVNG/E, CHTS, ULSAM, and the Vascular Surgery Departments in Braga and CHSJ Hospitals. The authors also wish to thank all patients who agreed to participate in this study.

\section{Declaration of conflicting interests}

The author(s) declared no potential conflicts of interest with respect to the research, authorship, and/or publication of this article.

\section{Funding}

The author(s) disclosed receipt of the following financial support for the research, authorship, and/or publication of this article: This study was conducted at Psychology Research Centre (PSI/01662), University of Minho, and supported by the Portuguese Foundation for Science and Technology and the Portuguese Ministry of Science, Technology and Higher Education through national funds and cofinanced by FEDER through COMPETE2020 under the PT2020 Partnership Agreement (POCI-01-0145FEDER-007653). This work was supported by a 
grant (SFRH/BD/87704/2012) from the Portuguese Foundation for Science and Technology.

\section{References}

Akca AT and Cinar S (2008) Comparison of psychosocial adjustment in people with diabetes with and without diabetic foot ulceration. Australian Journal of Advanced Nursing 25(4): 87-96.

Apelqvist J, Bakker K, van Houtum WH, et al. (2008) Practical guidelines on the management and prevention of the diabetic foot: Based upon the International Consensus on the Diabetic Foot (2007) Prepared by the International Working Group on the Diabetic Foot. Diabetes/ Metabolism Research and Reviews 24(1): 181-187.

Apelqvist J, Larsson J and Agardh CD (1993) Long term prognosis for diabetic patients with foot ulcers. Journal of Internal Medicine 233: 485-491.

Araújo F, Pais-Ribeiro L, Oliveira A, et al. (2007) Validação do Índice de Barthel numa amostra de idosos não institucionalizados [Validation of the Barthel Index in a sample of non-institutionalized elderly]. Revista Portuguesa de Saúde Pública 25(2): 59-66.

Armstrong DG, Lavery LA, Wrobel JS, et al. (2008) Quality of life in healing diabetic wounds: Does the end justify the means? Journal of Foot \& Ankle Surgery 47(4): 278-282.

Armstrong DG, Nguyen HC, Lavery LA, et al. (2001) Off-loading the diabetic foot wound: A randomized clinical trial. Diabetes Care 24(6): 1019-1022.

Armstrong DG, Wrobel $\mathrm{J}$ and Robbins JM (2007) Guest Editorial: Are diabetes-related wounds and amputations worse than cancer? International Wound Journal 4(4): 286-287.

Ashford RL, McGee P and Kinmond K (2000) Perception of qualify of life by patients with diabetic foot ulcers. The Diabetic Foot Journal 3: $150-155$.

Bally K, Campbell D, Chesnick K, et al. (2003) Effects of patient-controlled music therapy during coronary angiography on procedural pain and anxiety distress syndrome. Critical Care Nurse 23(2): 50-58.

Bengtsson L, Jonsson M and Apelqvist J (2008) Wound-related pain is underestimated in patients with diabetic foot ulcers. Journal of Wound Care 17(10): 433-435.
Bradbury S and Price P (2011) The impact of diabetic foot ulcer pain on patient quality of life. Wounds UK 7(4): 32-49.

Carrington AL, Mawdsley SKV and Morely M (1995) The psychological assessment of diabetic people with or without foot ulcers or lower limb amputations. In: Hotta N, Greene DA, Ward JD, et al. (eds) Diabetic Neuropathy: New Concepts and Insights. Oxford: Elsevier Science, p. 159.

Carrington AL, Mawdsley SKV, Morley M, et al. (1996) Psychological status of diabetic people with or without lower limb disability. Diabetes Research and Clinical Practice 32(1-2): 19-25.

Chapman Z, Shuttleworth C and Huber JW (2014) High levels of anxiety and depression in diabetic patients with Charcot foot. Journal of Foot \& Ankle Research 7: 22.

Douglas V (2001) Living with a chronic leg ulcer: An insight into patients' experiences and feelings. Journal of Wound Care 10(9): 355-360.

Edmonds M and Foster AM (2006) ABC of wound healing. Diabetic foot ulcers. British Medical Journal 332: 407-410.

Engel GL (1977) The need for a new medical model: A challenge for biomedicine. Science 196(4286): 129-136.

Fejfarová V, Jirkovská A, Dragomirecká E, et al. (2014) The diabetic foot have a significant impact on selected psychological or social characteristics of patients with diabetes mellitus? Journal of Diabetes Research 2014: 371938 (7 pp.).

Ferreira LP, Ferreira LN and Pereira LN (2012) Medidas sumário física e mental de estado de saúde para a população portuguesa [Physical and mental summary measures of health state for the Portuguese population]. Revista Portuguesa de Saúde Pública 30(2): 163-171.

Fortin M, Bravo G, Hudon C, et al. (2006) Relationship between multimorbidity and health related quality of life of patients in primary care. Quality of Life Research 15(1): 83-91.

Frykberg RG, Armstrong DG, Giurini J, et al. (2000) Diabetic foot disorders: A clinical practice guideline. Journal of Foot \& Ankle Surgery 39(5): 1-60.

Goodridge D, Trepman E and Embil JM (2005) Health-related quality of life in diabetic patients with foot ulcers: Literature review. Journal of Wound, Ostomy and Continence Nursing 32(6): 368-377. 
Goodridge D, Trepman E, Sloan J, et al. (2006) Quality of life of adults with unhealed and healed diabetic foot ulcers. Foot \& Ankle International 27: 274-280.

IBM Corporation (2013) IBM SPSS Statistics for Windows, Version 22.0 [Computer software]. Armonk, NY: IBM Corporation.

Ikem RT, Ikem IC and Ola BA (2009) Relationship between depression, cognitive function and quality of life of Nigerians with diabetic foot ulcers. A preliminary controlled study. Acta Endocrinologica 5(1): 75-83.

International Diabetes Federation (IDF) (2013) Diabetes Atlas (6th edn). Available at: http:// www.idf.org/sites/default/files/EN_6E_Atlas_ Full_0.pdf

Ismail K, Winkley K, Stahl D, et al. (2007) A cohort study of people with diabetes and their first foot ulcer: The role of depression on mortality. Diabetes Care 30(6): 1473-1479.

Iversen MM, Midthjell K, Tell GS, et al. (2009) The association between history of diabetic foot ulcer, perceived health and psychological distress: The Nord-Trøndelag Health Study. BMC Endocrine Disorders 9: 18.

Johannesson A, Larsson GU, Ramstrand N, et al. (2009) Incidence of lower limb amputation in the diabetic and nondiabetic general population: a 10-year population-based cohort study of initial unilateral and contralateral amputations and reamputations. Diabetes Care 32(2): 275-280.

Mahoney FI and Barthel DW (1965) Functional evaluation: The Barthel Index. Maryland State Medical Journal 14: 61-65.

Margolis DJ, Malay DS and Hoffstad OJ (2011) Economic Burden of Diabetic Foot Ulcers and Amputations (Data points publication series). Rockville, MD: Agency for Healthcare Research and Quality. Available at: http://www. ncbi.nlm.nih.gov/books/NBK65152/

Madanchi N, Tabatabaei-Malazy O, Pajouhi M, et al. (2013) Who are diabetic foot patients? A descriptive study on 873 patients. Journal of Diabetes \& Metabolic Disorders 12(36): 1-6.

Mayfield JA, Reiber GE, Sanders LJ, et al. (2003) Preventive foot care in people with diabetes. Diabetes Care 26(Suppl. 1): S78-S79.

Meijer JW, Trip J, Jaegers SM, et al. (2001) Quality of life in patients with diabetic foot ulcers. Disability and Rehabilitation 23(8): 336-340.

Monami M, Longo R, Desideri CM, et al. (2008) The diabetic person beyond a foot ulcer: Healing, recurrence, and depressive symptoms. Journal of the American Podiatric Medical Association 98(2): 130-136. Available at: http://dx.doi. org/10.7547/0980130

Nabuurs-Franssen MH, Huijberts MSP, Nieuwenhuijzen Kruseman AC, et al. (2005) Health-related quality of life of diabetic foot ulcer patients and their caregivers. Diabetic Foot 48(9): 1906-1910.

Nam S, Chesla C, Stotts NA, et al. (2011) Barriers to diabetes management: Patient and provider factors. Diabetes Research and Clinical Practice 93(1): 1-9.

Pais-Ribeiro J, Silva I, Ferreira T, et al. (2007) Validation study of a Portuguese version of the Hospital Anxiety and Depression Scale. Psychology, Health \& Medicine 12(2): 225-237.

Portuguese Society of Diabetes (2015) Diabetes: Factos e Números 2014: Relatório Anual do Observatório Nacional da Diabetes [Diabetes: Facts and Numbers 2014: Annual report from Diabetes National Observatory]. Available at: http://spd.pt/images/ond_2015.pdf

Price P (2004) The diabetic foot: Quality of life. Clinical Infectious Diseases 36(2): 129-131.

Ragnarson Tennvall G and Apelqvist J (2000) Health-related quality of life in patients with diabetes mellitus and foot ulcers. Journal of Diabetes and Its Complications 14(5): 235-241.

Reiber GE, Lipsky BA and Gibbons GW (1998) The burden of diabetic foot ulcers. American Journal of Surgery 176(Suppl. 2A): 5S-10S.

Ribu L and Wahl A (2004) Living with diabetic foot ulcers: A life of fear, restrictions, and pain. Ostomy Wound Management 50(2): 57-67.

Ribu L, Hanestad BR, Moum T, et al. (2007) A comparison of the health-related quality of life in patients with diabetic foot ulcers, with a diabetes group and a nondiabetes group from the general population. Quality of Life Research 16(2): 179-189.

Siersma V, Thorsen H, Holstein PE, et al. (2013) Importance of factors determining the low health-related quality of life in people presenting with a diabetic foot ulcer: The Eurodiale study. Diabetic Medicine 30(11): 1382-1387.

Valensi P, Girod I, Baron F, et al. (2005) Quality of life and clinical correlates in patients with diabetic foot ulcers. Diabetes \& Metabolism 31(3): 263-271.

Vedhara K, Miles JN, Wetherell MA, et al. (2010) Coping style and depression influence the healing 
of diabetic foot ulcers: Observational and mechanistic evidence. Diabetologia 53(8): 1590-1598.

Vileikyte L, Leventhal H, Gonzalez JS, et al. (2005) Diabetic peripheral neuropathy and depressive symptoms: The association revisited. Diabetes Care 28(10): 2378-2383.

Vileikyte L, Peyrot M, Bundy EC, et al. (2003) The development and validation of a neuropathyand foot ulcer-specific quality of life instrument. Diabetes Care 26(9): 2549-2555.

Ware JE, Snow KK, Kosinski M, et al. (1993) SF36 Health Survey: Manual and Interpretation Guide. Boston, MA: The Health Institute, New England Medical Center.

Williams LH, Rutter CM, Katon WJ, et al. (2010) Depression and incident diabetic foot ulcers: A prospective cohort study. American Journal of Medicine 123: 748-754.

World Health Organization (WHO) (2009) Milestones in Health Promotion: Statements from Global Conferences. Available at: http:// www.who.int/healthpromotion/Milestones Health_Promotion_05022010.pdf

Yekta Z, Pourali R and Ghasemi-rad M (2011) Comparison of demographic and clinical characteristics influencing health-related quality of life in patients with diabetic foot ulcers and those without foot ulcers. Diabetes, Metabolic Syndrome and Obesity 4: 393-399.

Zigmond AS and Snaith RP (1983) The hospital anxiety and depression scale. Acta Psychiatrica Scandinavica 67: 361-370. 